\title{
FECUNDIDAD Y ACTIVIDAD FEMENINA EN ESPAÑA: 1980-1995
}

\author{
Jimena Puy Cabetas
}

Universidad Complutense de Madrid

E-mail: jpuy@nexo.es

\section{RESUMEN}

España tiene uno de los índices sintéticos de fecundidad (promedio de hijos por mujer) más bajos del mundo. La tasa de actividad femenina es también una de las más bajas respecto a los demás países industrializados. No obstante, la tasa de actividad aúna dos fenómenos contrarios: empleo y desempleo.

Tras una revisión de los estudios empíricos que han demostrado evidencia acerca de la relación existente entre fecundidad y actividad femenina en los países industrializados, este trabajo presenta un primer acercamiento, a nivel macro, a los datos que nos revelan la evolución del mercado de trabajo en nuestro país con el fin de llegar a esclarecer la posible influencia que ésta ha podido tener como determinante de la fecundidad.

\section{INTRODUCCIÓN}

Desde que la fecundidad inició su descenso más abrupto llegando a alcanzar niveles que harían peligrar el reemplazo generacional, la incorporación masiva de la mujer al mercado de trabajo ha sido y es considerada como un factor determinante. La dirección causal entre estas dos variables no parece todavía clara. ¿Es el descenso de la fecundidad lo que ha permitido que la mujer trabaje fuera del hogar o es el hecho de que la mujer trabaje fuera del hogar lo que ha disminuido su deseo de tener hijos? Pero la interdependencia entre estas dos variables parece indiscutible, ya que no sólo puede haber una 
relación directa de una hacia la otra, sino que la relación puede y parece ser mutua, ya que la formación de la familia y la participación laboral son dos procesos dinámicos que interactúan constantemente (Bernhardt, 1993).

Ahora bien, ¿qué sucede cuando la mujer quiere trabajar y no puede? En el último cuarto de siglo las cifras de desempleo en los países industrializados consideradas "aceptables» han ido ascendiendo. En algunos casos, como en el de nuestro país, las cifras son alarmantes. El paro afecta más a los jóvenes y a las mujeres. El máximo alcanzado fue en 1995: la cifra correspondiente al grupo de mujeres entre veinte y veinticuatro años, 46,7 por $100^{1}$. ¿Cómo se puede, entonces, medir el efecto del paro como posible determinante de la caída de la fecundidad en España?

Este trabajo se enmarca dentro del denominado modelo de elección racional, en el cual se presume que el comportamiento final es el resultado de las decisiones que tomamos, teniendo en cuenta nuestras preferencias y sus limitaciones. Bajo este supuesto, el aumento de la tasa de actividad femenina es considerado como reflejo del aumento del deseo de las mujeres por participar en el mercado de trabajo, y el desempleo, como limitación a ese deseo.

Según las distintas encuestas realizadas por el CIS en nuestro país (1981, 1985, 1989, 1991 y 1994) ${ }^{2}$ en las que se preguntó acerca del número de hijos deseados, la media estimada de todo el período es de 2,4 hijos. En 1980 el promedio de hijos por mujer era de 2,2; en 1995, de 1,2. Se puede decir que las mujeres españolas tienen, en términos agregados, desde 1990 y hasta la actualidad, un hijo menos del que desean.

El objeto de este trabajo es saber si existen indicios, a nivel macro, que permitan esclarecer las diferencias existentes entre mujeres activas e inactivas en cuanto a su comportamiento reproductivo y poder así contribuir a la explicación de la brecha existente entre el número de hijos deseados y el número de hijos que se tienen, de un hijo por mujer.

El primer apartado presenta el método empleado en el análisis de los datos y las fuentes de información. El segundo describe el marco analítico en el que este trabajo se inserta. El tercero y cuarto tratan la evolución de la fecundidad y de la participación laboral femenina desde 1980 hasta 1995 . Ambos fenómenos (fecundidad y actividad femenina) serán estudiados con especial atención al grupo de mujeres en edades comprendidas entre los veinte y los treinta y nueve años. El apartado quinto analiza la relación entre estas dos variables, con

1 EPA, INE. Media anual 1995.

2 CIS: Evolución del sistema de valores en España, Estudio núm. 1263, Madrid, 1981.

CIS: Actitudes y opiniones de los españoles frente a la natalidad, Estudio núm. 1474, Madrid, 1985.

CIS: Encuesta general de población, Estudio núm. 1841, Madrid, 1989.

CIS: Interrupción voluntaria del embarazo, Estudio núm. 1968, Madrid, 1991.

CIS: Familia (International Social Survey Programme), Estudio núm. 2113, Madrid, 1994. 
el fin de proceder a valoraciones que darán paso a las conclusiones expuestas en el sexto apartado.

\section{METODOLOGÍA}

Los datos de la evolución de la fecundidad en España que se presentan son los publicados por la edición del Consejo de Europa (1998) sobre cambios demográficos recientes, facilitados a su vez por el Instituto Nacional de Estadística español. Se presentan datos totales desde 1960 (evolución del promedio de hijos por mujer o índice sintético de fecundidad). Las tasas de fecundidad específicas que se presentan son las pertenecientes a la mujeres en edades comprendidas entre veinte y treinta y nueve años de edad (el 90 por 100 de los nacimientos en 1980 correspondía a mujeres de este grupo, y en 1995, el 95 por 100 de los mismos). Estas tasas de fecundidad específicas se exponen desde 1977, año en el que se inició la caída más abrupta de la fecundidad. También se hace uso, en las conclusiones, de la última estimación acerca del tamaño de la descendencia final de las mujeres nacidas entre 1960 y 1965 , publicadas por el Consejo de Europa en 1998.

Los datos correspondientes a la evolución de la participación femenina en España son los pertenecientes a la Encuesta de Población Activa (EPA), publicados por el Instituto Nacional de Estadística. Esta encuesta está diseñada acorde con los criterios establecidos por la Organización Internacional del Trabajo. Se presentan cifras correspondientes a las tasas totales y específicas a los grupos de edad (para los grupos en edades comprendidas entre los veinte y los treinta y nueve años) para el período 1980-1995. Los datos que aquí se exponen pertenecen a las series homogeneizadas debido a que dos cambios metodológicos, en 1987 y 1991, hicieron que parte de los datos correspondientes a aquellos considerados inactivos en el período anterior a 1987 se consideraran activos a partir de entonces. Nuevamente, en 1991 el término «activos» se vio ampliado, reduciendo aún más los considerados inactivos.

La tasa de mujeres activas es la resultante del número total (para las cifras específicas el total en cada grupo de edad) de mujeres ocupadas, más mujeres en busca de empleo, dividido por la población femenina en edad de trabajar (iguales y mayores de dieciséis años). La tasa de paro es la resultante del número de mujeres en busca de empleo (paradas), dividido por la población activa (paradas, más ocupadas). La tasa de ocupación es la resultante del número total de ocupadas dividido por la población femenina en edad de trabajar (iguales y mayores de dieciséis años).

Para poder proceder a valoraciones acerca de la relación entre actividad femenina y fecundidad, los datos que se exponen han sido extraídos del Movimiento Natural de Población (MNP), publicados por el Instituto Nacional de Estadística, en concreto los correspondientes a la clasificación: "Nacimientos según actividad económica y edad de la madre», en 1980 y 1995 . Se incluyen 
nacimientos de mujeres casadas y no casadas (la proporción de nacimientos fuera del matrimonio ha pasado del 4 por 100 en 1980 al 11 por 100 en 1995). Esta clasificación permite establecer las diferencias entre el número de los hijos nacidos de mujeres atendiendo al criterio de: activas e inactivas.

Como paso posterior dentro de la exposición de datos y con el fin de proceder a valoraciones, el número total de nacidos en cada grupo de edad extraído del MNP se ha dividido entre el total de mujeres en cada grupo atendiendo a la actividad económica de la madre. Estos totales, de mujeres activas e inactivas, han sido también extraídos de la EPA. Este paso es fundamental para poder valorar los datos que desde el nivel macro se han observado. Los resultados de esta fase del estudio se consideran como un posible nexo entre el análisis a nivel macro y micro.

Conceptos básicos aplicados a la situación del mercado de trabajo ${ }^{3}$ :

Tasa de actividad femenina $=\frac{\text { Mujeres ocupadas }+ \text { Mujeres paradas }}{\text { Mujeres potencialmente activas }(\leq 16)}$

Tasa de ocupación femenina $=\frac{\text { Mujeres ocupadas }}{\text { Mujeres potencialmente activas }(\leq 16)}$

Tasa de paro femenina $=\frac{\text { Mujeres paradas }}{\text { Mujeres activas (ocupadas }+ \text { paradas })}$

\section{MARCO ANALÍTICO}

Las teorías que han ofrecido una explicación a la caída de la fecundidad en los países industrializados y que han considerado la participación laboral femenina como posible determinante han sido en su mayoría teorías con un enfoque económico o sociológico. El enfoque económico toma como premisa el carácter racional de las decisiones que tomamos, mientras que el enfoque sociológico (también denominado normativo) parte de la importancia de los valores como principal determinante en nuestras actitudes. El estudio de ambos enfoques ha sido fundamental para ofrecer una perspectiva socio-económica que adopta las aportaciones más relevantes de ambos.

La principal crítica de los sociólogos a los economistas se basa en el reduccionismo de éstos al tomar el comportamiento de individuos como simples actos, en la valoración de tales en términos estrictamente monetarios y en la

\footnotetext{
3 Tasas utilizadas en la EPA de acuerdo a los criterios propuestos por la OIT.
} 
poca importancia atribuida a los valores como predeterminante de nuestras acciones.

El modelo de elección racional, tal como se describía en la introducción, presume que nuestro comportamiento es el resultado de las decisiones que tomamos, teniendo en cuenta nuestras preferencias y sus limitaciones. Este modelo, aunque tiene sus orígenes en el modelo utilizado en los análisis económicos de la fecundidad (Becker, 1960, 1976, 1981), se presenta en este trabajo con aportaciones resultantes del estudio del enfoque normativo. El modelo inicial económico ha carecido de un criterio común entre los economistas a la hora de establecer los valores que rigen el comportamiento reproductivo, tal como ellos mismos han reconocido (Becker y Barro, 1988).

El modelo de elección racional que aqui se presenta (preferencias $\rightarrow$ limitaciones $\rightarrow$ comportamiento final), inserto en la teoría preferencial, establece distintas opciones que las mujeres mantienen acerca de su posicionamiento en el mercado de trabajo y a su deseo de tener hijos.

La teoría preferencial (Hakim, 1998), que a continuación se expone, se presenta desde el enfoque sociológico y desde el intento de conseguir un enfoque socio-económico en las ciencias sociales que revierta en un análisis más completo.

La presunción de esta teoría es que desde que el alcance a métodos anticonceptivos se ha generalizado en los países desarrollados, las mujeres han entrado en una nueva era en la que el control sobre su comportamiento reproductivo les permite elegir libremente sobre sus preferencias entre trabajo y familia. Las preferencias son ahora más importantes que cuando nuestra actitud hacia el trabajo tenía como único motor el factor económico.

La teoría preferencial identifica el cambio de actitud que la mujer tiene respecto a su participación en el mercado laboral y a su deseo de tener hijos. Establece una tipología que permite analizar las diferentes posiciones de la mujer en la sociedad y a través del cual se permite establecer un modelo que facilita estudios comparativos a nivel regional y nacional (Cuadro 1).

Respecto a su contenido ambas disciplinas se complementan puesto que el modelo racional que los economistas exponen da cabida a los factores normativos (o culturales) que determinan las cualidades de las preferencias, la asimilación de las limitaciones como tales y su resultado en el comportamiento final. 


\section{CUADRO 1}

Una clasificación de las preferencias de las mujeres

\begin{tabular}{ccc}
\hline Centradas en la familia & Compaginan familia y empleo & Centradas en el empleo \\
\hline Varía entre el 10-30\% & Varía entre el $40-80 \%$ & Varía entre el 10-30\% \\
\hline
\end{tabular}

La prioridad fundamental: La prioridad fundamental: niños y familia. poder combinar trabajo y familia.

Prefieren no tener un empleo.

Formación conseguida para la «dote intelectual».

El número de hijos que tienen está influenciado por la política social en el ámbito familiar pero no responden a políticas que facilitan su adaptación con el mercado laboral.
La prioridad fundamental: trabajo.

Casi todas las mujeres sin hijos pertenecen a este grupo.

Comprometidas totalmente al trabajo.

Gran formación proyectada al empleo.

No responden ante los cambios de políticas sociales y familiares.

Responden ante las posibilidades de promoción económica, social, etc.
Responden a las políticas sociales, familiares y directas de empleo, tales como:

- deducciones fiscales,

- programas de formación,

- horarios escolares compatibles con su empleo,

- cambios legislativos que promuevan el empleo femenino,

- respaldo público en la promoción de la mujer,

- facilidades para tener flexibilidad laboral,

- expectativas de crecimiento y prosperidad.

FuENTE: C. HAKIM (1998): «Developing a sociology for the twenty-first century: Preference Theory», en British Journal of Sociology, núm. 49, Issue núm. 1, London School of Economics, marzo, pp. 138. 


\section{LA FECUNDIDAD EN ESPAÑA}

España, al igual que todos los países industrializados, ha experimentado un descenso de la fecundidad que hace peligrar el reemplazo generacional. Algunos países presentan indicios de recuperación y, según la opinión de expertos, las bajas cifras observadas en el índice sintético de fecundidad (ISF) obedecen en gran medida a una postergación de la edad en la que las mujeres tienen sus hijos.

Según lo observado en el gráfico II, a partir de 1965 se inicia una leve disminución de la fecundidad seguida de una caída más pronunciada en 1977, pasando de casi tres hijos por mujer (2,8 en 1976) a 1,2 en 1995. España, junto con Italia e Irlanda, han protagonizado las caídas más espectaculares de la fecundidad en el último cuarto de siglo.

\section{GRÁFICO II}

Evolución del Indice Sintético de Fecundidad (o promedio de hijos por mujer) en España: 1960-1995

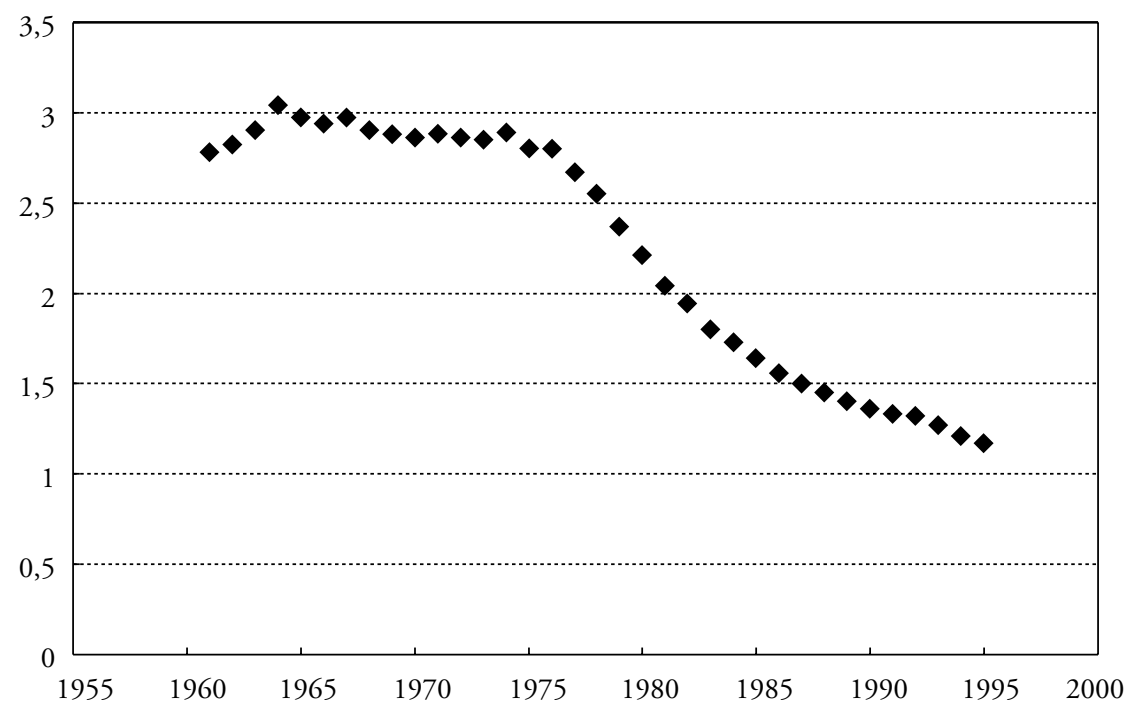

FuENTE: Recent Demographic Changes, Consejo de Europa, 1998:375. Datos ofrecidos por el INE. 
En el gráfico III se puede observar con más detalle características más precisas de esta caída. Atendiendo al comportamiento reproductivo de las mujeres que se encuentran entre los grupos de edad veinte y treinta y nueve años (grupo en el que se encuentra el "grueso" de los nacimientos), se puede observar las diferencias entre ellos.

Desde 1976, para el grupo de mujeres en edades comprendidas entre veinte y veinticuatro años, el número de nacimientos se ha visto reducido en un 78 por 100, pasando de 144 nacimientos por cada 1.000 mujeres en ese grupo de edad a 31 en 1995. La reducción para el siguiente grupo (25-29) ha sido del 55 por 100; en 1976 la cifra era de 187,4 nacimientos por cada 100 mujeres y en 1995 de 82,7. Los nacimientos de las mujeres entre treinta y treinta y cuatro años se redujeron en un 33 por 100 entre 1976 y 1995 (han pasado de ser 119 nacimientos por cada 1.000 mujeres a 78,8). Por último, los comprendidos en el grupo de mujeres entre treinta y cinco y treinta y nueve años han visto reducido su número en un 52 por 100 (la cifra observada en 1976 era de 60,8 hijos por cada 1.000 mujeres insertas en ese grupo de edad y en 1995 fue de 29,0).

\section{GRÁFICO III}

Evolución de las tasas especificas de fecundidad de las mujeres en edades entre (20-39): 1976-1995

(Nacidos vivos por cada 1.000 mujeres a edades específicas)

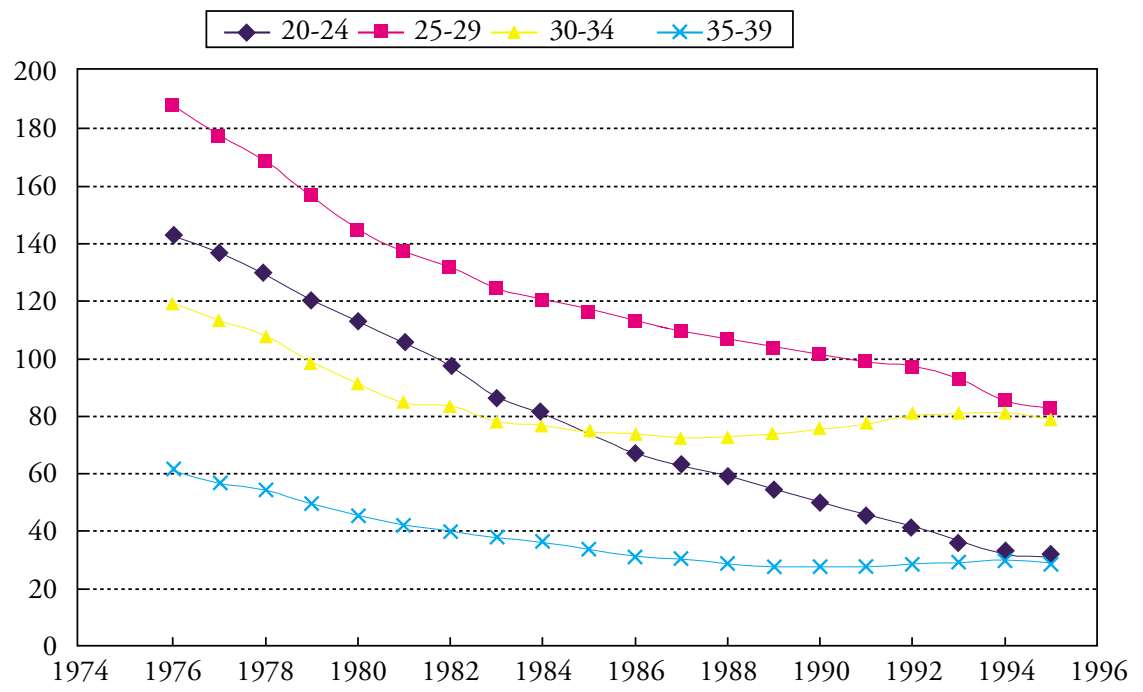

Fuente: Recent Demographic Changes, Consejo de Europa, 1998:375. Datos ofrecidos por el INE. 
Aunque todos los nacimientos han disminuido, algunas tasas específicas presentan indicios de recuperación, tal como se ve en el gráfico III. En concreto, el grupo de mujeres de edades comprendidas entre treinta y treinta y cuatro años tiene un ascenso en sus tasas a partir 1990 que, aunque leve, avala la presunción de que pueda seguir ofreciendo síntomas de recuperación y elevar así el tamaño de la descendencia de la cohorte. El siguiente grupo de mujeres entre treinta y cinco y treinta y nueve años también presenta una recuperación pero en este caso mucho más leve. A partir de 1992 consigue aumentar su tasa, pasando de 27,5 nacimientos por cada 1.000 mujeres a 29 en 1995. En cualquier caso, parece que ambas tendencias (para los grupos comprendidos entre treinta y treinta y nueve años) continúan a la alza.

Por el contrario, los datos observados para los grupos de mujeres entre veinte y veintinueve años no presentan ningún indicio de recuperación. Según la trayectoria de ambas tendencias y a pesar de que el ritmo de aceleración parece haberse ralentizado, a lo largo del período ambas tasas no han mostrado ningún síntoma de recuperación.

\section{ACTIVIDAD FEMENINA EN ESPAÑA}

La mujer siempre ha trabajado en el campo, en la fábrica, en el comercio familiar, en la oficina y/o en casa. Precisamente por la amplitud y complejidad del término "trabajo» el primer paso dentro de este apartado es definir el término de «actividad» ${ }^{4}$. La definición elegida es la de la OIT (Organización Internacional del Trabajo), que es la misma que se aplica en España en la Encuesta de Población Activa. Por «activos» se entiende la parte de la población en edad de trabajar (con edad igual y superior a dieciséis años), que bien se encuentra trabajando o buscando empleo. Por parados se entiende a la parte de la población que desea trabajar pero no encuentra empleo. Por inactivos se entiende la parte de la población que, potencialmente activa (iguales y mayores de dieciséis años), no quiere o se ve imposibilitada para trabajar. Este tipo de distinciones se realiza en nuestro país desde 1964, año de creación de la EPA. No obstante, la obtención de los datos sobre desempleo es sólo posible a partir de 1977.

Dentro de este punto número 4 se presenta la evolución de las tasas de actividad y desempleo totales para hombres y mujeres en el período que ocupa esta presentación (1980-1995), para poder valorar las diferencias en la evolución de las tasas de ambos colectivos. Los datos corresponden a los publicados por la Encuesta de Población Activa (EPA) por el Instituto Nacional de Estadística. Debido a los cambios metodológicos de dicha encuesta, se presentan los correspondientes a las series homogeneizadas.

4 Sobre la conceptualización del trabajo de la mujer en la sociedad contemporánea ver M. A. DURÁN: "El trabajo invisible en España: aspectos económicos y normativos», en Revista de Estudios Sociales y de Sociología Aplicada, núm. 105, Madrid, 1996, pp. 137-157. 
Según los datos presentados en el gráfico IV, el incremento de la tasa de actividad femenina ha sido, dentro del período estudiado (1980-1995), del 33 por 100. En 1980 la tasa de actividad femenina era de un 27,1 por 100 respecto a la población potencialmente activa femenina y en 1995 llegó a ser de un 36,1 . Por su parte, el colectivo masculino ve reducida su tasa de actividad en un 13 por 100 al final del período. Su tasa era en 1980 de 72,2 y en 1995 es del 62,7 por 100 respecto al total de la población potencialmente activa.

Ahora bien, la tasa de actividad aúna dos fenómenos contrarios: empleo y desempleo. La tasa de actividad es la resultante de la suma del número de ocupados y parados, dividido por la población potencialmente activa igual y mayor a dieciséis años. El gráfico número $\mathrm{V}$ muestra la evolución de las tasas de paro masculinas y femeninas en el período estudiado. La tasa de paro es la resultante del número de parados dividido por la suma de parados y ocupados, es decir, dividido por la población activa. Hay que tener en cuenta, al interpretar los datos que aquí se muestran, que a partir de 1980 el aumento que la tasa

\section{GRÁFICO IV}

Evolución de las tasas de actividad masculinas y femeninas: 1980-1995

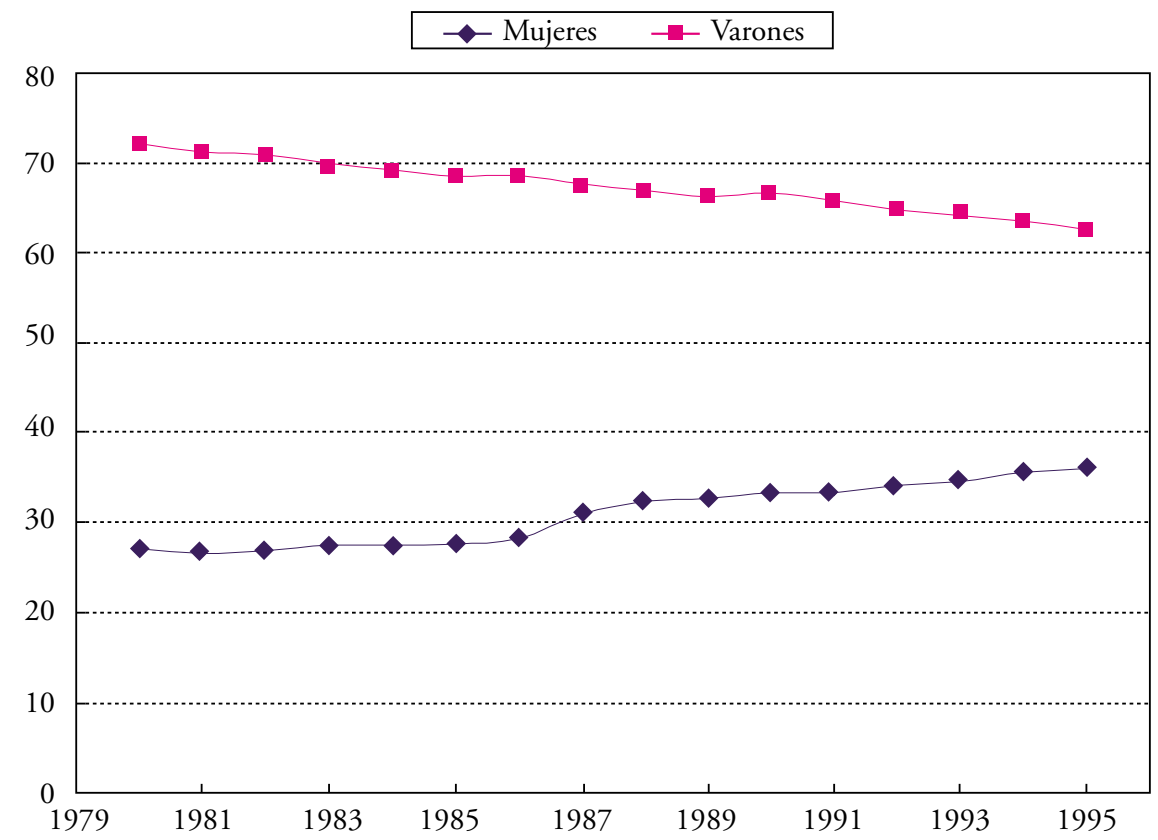

FUENTE: EPA, INE. Tasas correspondientes al 2. ${ }^{\circ}$ trimestre de cada año. 
de población femenina activa adquiere es debido a que el deseo de incorporación y mantenimiento, dentro del mercado de trabajo por parte del colectivo femenino, aumenta.

Desde 1980 y hasta 1995, nuestro país ha vivido tres fases económicas distintas que se describen a continuación: 1980-1984, 1985-1991 y 1992-1995.

1980-1984. Con la crisis del petróleo, España entra, al igual que el resto de los países industrializados, en un período de crisis económica, iniciado en 1975. Las tasas más altas de crecimiento económico (tomadas por el PIB) son inferiores a las más bajas observadas desde 1961 hasta 1974. A tal crisis le acompañan también los costes económicos derivados de la transición política a la democracia que impedirá reaccionar de forma rápida y ajustarse a los nuevos cambios. Los «Pactos de la Moncloa» de 1977 son un claro ejemplo del intento de reconducir la situación económica. Se sumaría también el segundo impacto originado por la subida del petróleo, que llega en momentos políticos delicados, impidiendo dar lugar al desarrollo de políticas económicas precisas, prolongándose así una situación de crisis que no vería indicios de recuperación hasta 1985 (Pampillón, 1994). Las tasas de paro reflejan claramente esta situación. La tasa de paro masculina aumenta pasando de un 10,7 por 100 de la población activa a un 20,3 por 100 en 1985 . Este aumento del 90 por 100 , a pesar de su importancia, es menor que el observado por el colectivo femenino que ve pasar su tasa de desempleo de un 12,2 por 100 en 1980 a un 24,8 en 1985 (aumento del 100 por 100).

1985-1991. A partir de 1985, España inicia un período de recuperación en el cual nuestra economía se abre definitivamente hacia el exterior, permitiendo ampliar la inversión extranjera. A ello se une la "puesta a punto" de las empresas españolas. Esta fase de crecimiento económico permite la creación de 400.000 empleos anuales. No obstante, y tal como aparece en el gráfico VI, la cifra de paro femenino sigue creciendo, aunque con un ritmo menor, hasta 1988. En 1985 su tasa era de 24,8 y en 1988 alcanzaría el 28 por 100 de la población activa, un aumento del 13 por 100 en tres años que iniciaría un descenso a partir de entonces, hasta 1992. Por su parte, la cifra de desempleo masculino parece ser fiel testigo de la recuperación económica e inicia en 1986 un descenso en su tasa de paro hasta 1991, alcanzando un 11,9 por 100 de la población activa respecto al 20,3 por 100 observado en 1985 . Un descenso del 41 por 100 que refleja claramente la situación del mercado de trabajo favorable para el colectivo masculino. Este descenso es claramente mayor comparado con la reducción que muestra el paro femenino en el período comprendido entre 1989 y 1991 , en el cual su tasa tan sólo se redujo en un 8 por 100 . En 1991 la tasa de paro masculino es de un 11,9 por 100 respecto a la población activa. La tasa femenina de paro es de 23,2. Esta tasa de paro femenino es casi un 100 por 100 superior que la masculina.

1992-1995. España vive nuevamente un nuevo período de crisis. Esta vez, no obstante, y en contra de la crisis vivida en el primer período (1980-1984 pero originada en 1975), se presentan en 1995, tras dos años, indicios de recuperación. 
La pérdida de puestos de trabajo y la casi inexistente creación de empleo son los dos fenómenos vividos en el mercado de trabajo. Las cifras de paro reflejan claramente la situación (1992-1994). La tasa de paro masculino aumenta un 68 por 100 (11,9 por 100 en 1991 y 20,0 por 100 en 1994). La tasa de paro femenina aumenta un 35 por 100, pasando de una tasa en 1991 de 23,2 a un 31,4 por 100 de la población activa en 1994. 1995 presenta, al igual que lo hizo 1989, síntomas de recuperación con una disminución, aunque leve (del 3 por 100), que la sitúa en un 30,3 por 100 de la población activa. También para la cifra de paro masculino presenta 1995 una disminución en su tasa, llegando en 1995 a tener un 18 por 100 de la población activa, lo cual supone una disminución del 10 por 100 en relación con la cifra de paro observada en 1994 del 20 por 100.

\section{GRÁFICO V}

Evolución de las tasas de paro masculinas y femeninas: 1980-1995

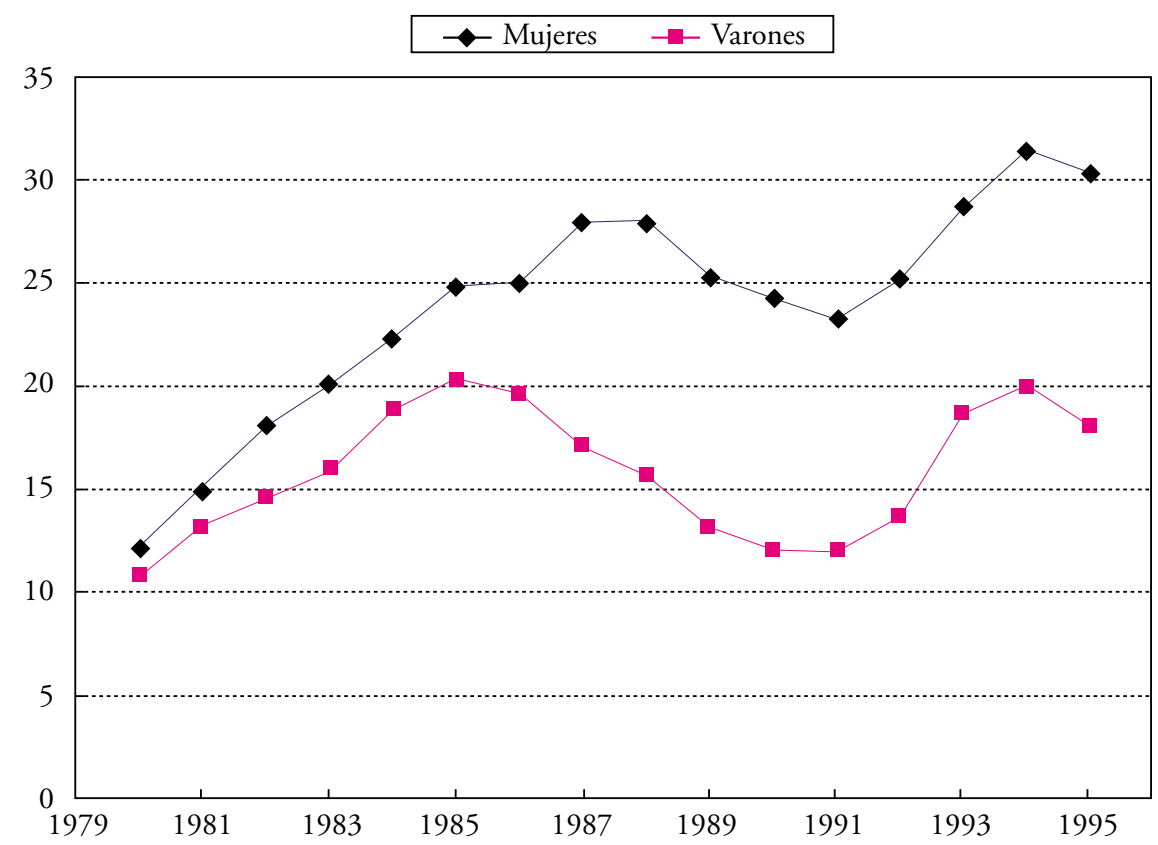

FUENTE: EPA, INE. Tasas correspondientes al 2. ${ }^{\circ}$ trimestre de cada año.

A lo largo de 1980-1995, y a tenor de lo observado en el gráfico V, la gravedad de la primera crisis económica afectó en casi igual medida a hombres y mujeres. Ambas tasas de paro prácticamente se doblaron. El período de recuperación económica vivido entre 1985 y 1991 benefició en mayor medida a los hombres, que vieron reducida su tasa de paro, en 1991, en un 41 por 100, mientras que la tasa de 
paro tan sólo se vio reducida para las mujeres en un 8 por 100 en 1991 respecto a la cifra observada en 1989, año en el que se inició un leve descenso. En la segunda crisis vivida entre 1992 y 1994 la tasa de paro aumentó más entre los hombres (un 68 por 100) que entre las mujeres (un 35 por 100). No obstante, al final del período (1980-1995) la cifra total de desempleo femenino es considerablemente mayor que la masculina (30,3 por 100 — cifra total de desempleo femenino-, y 18 por 100 — cifra de desempleo masculino-). Esta diferencia observada es especialmente relevante teniendo en cuenta que en 1980 la diferencia entre las dos tasas era mucho menor (12,2 para las mujeres y 10,7 para los hombres).

La evolución de la tasas totales, femenina y masculina, de actividad y desempleo, permite proceder de una forma más clara al análisis de las tasas específicas que muestro a continuación de actividad, ocupación y paro para los grupos de mujeres en edades comprendidas entre veinte y treinta y nueve años.

\subsection{Evolución de las tasas de actividad, ocupación y paro femeninas y específicas correspondientes a los grupos de edad comprendidos entre veinte y treinta y nueve años}

La tasa de actividad femenina, resultante de la suma del número de paradas más ocupadas, dividido por el número mujeres potencialmente activas ha ascendido en el período estudiado (1980-1995) en un 33 por 100, pasando de ser el 21,1 por 100 en 1980 al 36,2 por 100 de la población potencialmente activa en 1995 (medias anuales de cada año correspondiente) ${ }^{5}$.

Todos los grupos de edad presentados en el gráfico VI aumentan sus tasas de actividad entre 1980 y 1995 . No obstante, existen diferencias entre los distintos grupos que merecen atención.

El grupo de edad entre veinte y veinticuatro años presenta una evolución irregular. Hasta 1986 se mantiene casi constante. A partir de 1987 inicia un ascenso considerable pasando de una tasa de actividad de 54,9 en 1986 a 62,2 en 1989 (años de mayor crecimiento económico en España, entre 1980-1995). Este aumento del 13 por 100 sólo se observa hasta 1989. A partir de 1990 se inicia un descenso hasta 1995 que sitúa su tasa en 58,2 por 100 de la población potencialmente activa. Este descenso de 4 puntos porcentuales respecto a la cifra observada en 1989 supone una disminución en su tasa del 6 por 100 .

5 Anótese que al comparar tasas femeninas y masculinas se han utilizado las tasas correspondientes a los segundos trimestres de cada año, mientras que al hacer refererencia exclusivamente a las tasas femeninas se han utilizado las medias anuales. La razón es que, al encontrarse la mayoría de la creación de empleo femenino en el sector servicios (80 por 100) y aumentar éste especialmente en trimestres concretos (verano), el segundo trimestre parece ofrecer una tasa más «real» de la situación del mercado de trabajo al comparar los distintos sexos.

Al hacer referencia únicamente a las mujeres se han tomado las medias anuales que engloban todos los cambios ocurridos a lo largo del año. No obstante, se tome de una forma u otra, el aumento al que se hace referencia, la tasa de actividad femenina en este período (1980-1995) es del 33 por 100 en los dos casos. 
Al final del período la tasa de actividad correspondiente para el grupo de mujeres (20-24 años) apenas ha sufrido variaciones, excepto un leve ascenso.

El resto de los grupos ofrecen un aumento sin precedentes. Las mujeres entre 30 y 39 años doblan, entre 1980 y 1995, sus tasas de actividad. Estos dos grupos alcanzan cifras en 1995 en torno al 60 por 100 de la población potencialmente activa. El grupo correspondiente a 25-29 años también tiene un aumento considerable (del 70 por 100). En 1980 tiene una tasa del 42,2 por 100 de la población potencialmente activa, y en 1995 del 71,7 por 100. Es éste, el grupo de mujeres comprendidas entre veinticinco y veintinueve años, el que tiene la tasa de actividad más alta.

De los datos representados en los gráficos IV y VI se desprende que, si bien la tasa de actividad total femenina presentaba un aumento del 33 por 100 en el período estudiado (1980-1995), atendiendo a las tasas de actividad específicas por grupos de edad, las mujeres entre treina y treinta y nueve años han incrementado su participación en el mercado de trabajo en un 100 por 100 en el mismo período de tiempo, seguidas de las pertenecientes al grupo de edad 25-29 años (con un aumento del 70 por 100). La tasa correspondiente a las mujeres de edades comprendidas entre veinte y veinticuatro años apenas ha variado a lo largo de todo el período.

\section{GRÁFICO VI}

Evolución de las tasas específicas de actividad femenina para los grupos en edades entre 20-39 años: 1980-1995

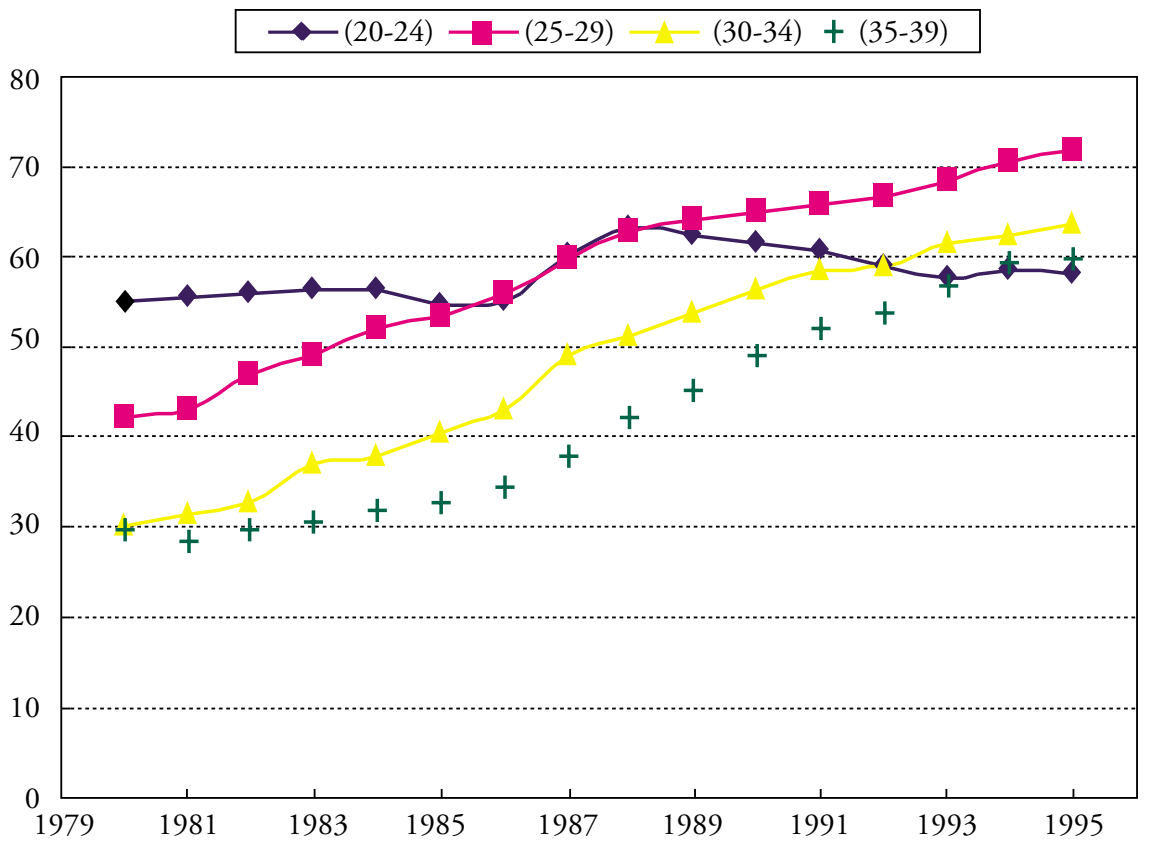

FuENTE: EPA, INE. Tasas correspondientes al 2. ${ }^{\circ}$ trimestre de cada año. 
No obstante, y tal como se ha señalado, la tasa de actividad engloba a parados y ocupados. Dos términos de naturaleza opuesta que requieren un análisis diferenciado en el momento de proceder a valoraciones en cuanto a su influencia para con otros fenómenos. Es éste precisamente el objetivo de este estudio, analizar la posible influencia que la evolución de la tasa de ocupación femenina y la tasa de paro femenina ha podido tener como determinante de la fecundidad. A continuación se exponen la evolución de ambas (tasa de ocupación y tasa de paro femeninas, específicas para los grupos de edad comprendidos entre 20-39 años).

Las tasas de ocupación específicas son el resultado de la división del número de mujeres ocupadas en cada grupo de edad por el conjunto de mujeres de ese mismo grupo de edad potencialmente activas.

Tal como se muestra en el gráfico VII, las tasas de ocupación femenina correspondientes a los grupos de edad (20-24) y (25-29) se han visto claramente influenciadas por las distintas fases económicas vividas en nuestro país, si bien hay una clara diferencia en la lectura de la evolución de las

\section{GRÁFICO VII}

Evolución de las tasas especificas de ocupación femenina para los grupos en edades entre 20-39 años: 1980-1995

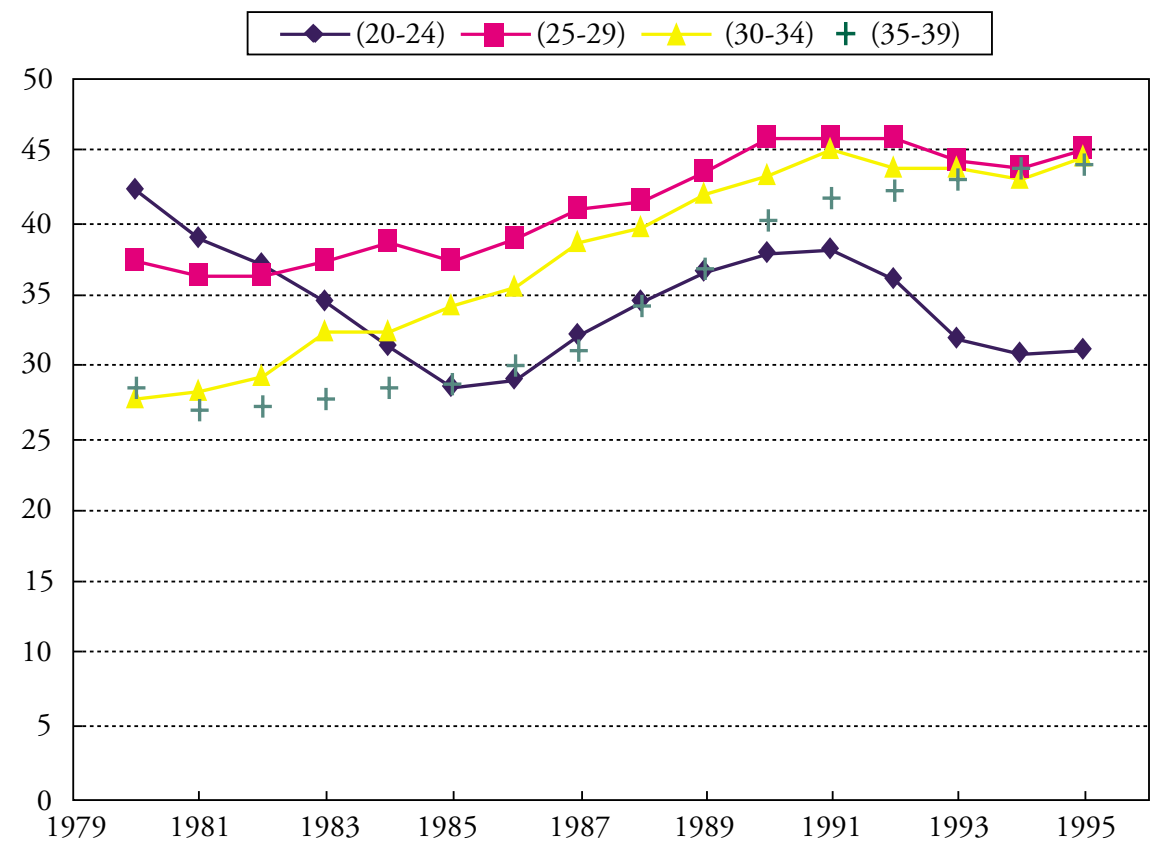

FUENTE: EPA, INE. Tasas correspondientes al 2. ${ }^{\circ}$ trimestre de cada año. 
tasas de estos dos grupos de edad. El grupo (20-24) es el único que llega a 1995 con una disminución en su tasa de ocupación de 11,1 puntos, lo que supone una disminución del 26,3 por 100 respecto a la tasa correspondiente a 1980. El grupo (25-29), aun habiendo estado expuesto a la influencia de las dos crisis vividas, finaliza el período en 1995 con un aumento de 7,6 puntos, lo que supone un aumento del 20,3 por 100 respecto a la tasa observada en 1980 .

Las tasas específicas de ocupación correspondientes a los grupos de mujeres en edades comprendidas entre 30-34 y 35-39 años parecen haber seguido un comportamiento distinto. A pesar de una leve disminución sufrida por el grupo 35-39 en el año 1981, ambas tasas han ascendido en el período observado. El grupo 30-34 (con una tasa de ocupación del 44,5 por 100 de la población potencialmente activa en 1995) ha experimentado un aumento en 1995 de 16,9 puntos, lo que supone un 61,2 por 100 de aumento en relación a la tasa observada en $1980(27,6)$. El grupo 35-39 concluye el período con un aumento en su tasa de 15,5 puntos, aumento del 54 por 100 en comparación a la tasa de 1980, situándose en 1995 en una tasa del 44 por 100 de la población potencialmente activa.

Una clara diferencia entre el comportamiento de las tasas (20-24, 25-29) y (30-34, 35-39) es que las primeras se han visto influenciadas por las distintas fases económicas vividas en este período, mientras que las segundas parecen haber iniciado un proceso en el que su situación laboral, en este caso su ocupación, debía estar lo suficientemente consolidada como para no verse afectada por los cambios económicos.

El cálculo de las tasas de paro femenino específicas resulta de dividir el número de paradas partido por la población activa, en la que se incluyen ocupadas y paradas, mientras que las tasas de actividad y ocupación se hallan, respectivamente, teniendo en su denominador la población potencialmente activa incluida en cada grupo de edad. Lo cual significa que los datos aquí expuestos y extraídos de la Encuesta de Población Activa revelan el tanto por ciento de parados respecto a la población activa, mientras que las tasas de actividad y ocupación se refieren a proporciones respecto a la población potencialmente activa (incluye inactivas, es decir, mujeres que pudiendo trabajar, no desean o no pueden trabajar).

Si se atiende al aumento sufrido en estas tasas de paro femenino en el período 1980-1985, período de crisis en nuestro país, se observa (gráfico VIII) que es precisamente aquí donde más ascendieron dichas tasas: la tasa de paro total femenino (12,9 en 1980 y 25,2 en 1985) y las pertenecientes a los grupos (20-24) y (30-34) se doblan; para el grupo 20-24 pasa de ser 23,5 en 1980 y 47,8 en 1985; para el grupo 30-34 pasa de ser de 8,6 en 1980 a 15,6 en 1985), mientras que las tasas de paro correspondientes a los grupos de edad (25-29) y (35-39) se triplican (para el grupo 25-29, 11,4 en 1980, y 29,9 en 1985; para el grupo de 35-39 años, 4,3 en 1980 y 12,2 en 1985).

El aumento de todas las tasas de paro femenino específicas representadas en el gráfico VIII es en el período 1980-1995 significativo. La tasa de paro 


\section{GRÁFICO VIII}

Evolución de las tasas específicas de paro femenino (sobre población activa) para los grupos en edades entre 20-39 años: 1980-1995

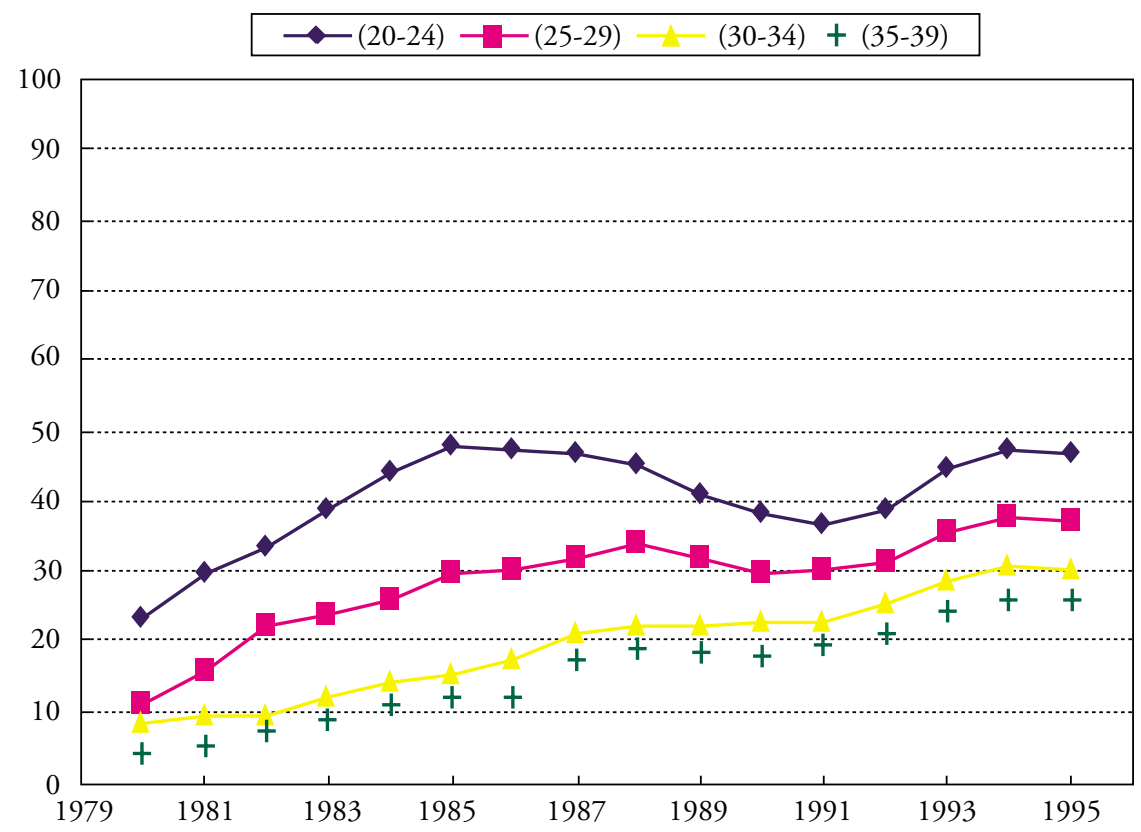

Fuente: EPA, INE. Tasas correspondientes al 2. ${ }^{\circ}$ trimestre de cada año.

correspondiente al grupo (20-25), si bien es la más alta de todas, tanto en 1980 (23,5 por 100 de la población activa) como en $1995(46,8)$, es la que menos aumento ha sufrido al final del período (99 por 100). Le sigue la tasa del grupo (25-29), con un aumento del 226 por 100; la del grupo (30-34), con un aumento del 250 por 100 , y por último, la tasa de paro correspondiente al grupo de 35 a 39 años, que experimenta una subida del 511 por 100.

Resumiendo, la tasa de actividad total femenina se ha visto incrementada en un 33 por 100 en el período 1980-1995, pasando de un 27,1 por 100 respecto a la población potencialmente activa femenina a un 36,08 por 100 en 1995 . Atendiendo a las tasas especificas de actividad femenina por edad, las correspondientes a los grupos (30-34) y (35-39) doblan su participación en el mercado laboral en el período estudiado. La tasa perteneciente al grupo (25-29), si bien ofrece también variaciones respecto a las diferentes fases económicas, llega a 1995 con un aumento en su tasa del 20,3 por 100 respecto a la tasa observada en 1980. Esta tasa (25-29) muestra el valor más alto de actividad con un 71,7 por 100 de la población potencialmente activa (gráfico VI). La correspondien- 
te al grupo (20-24) es la única que llega a 1995 con una disminución en su tasa equivalente al 26,3 por 100 respecto a 1980 , y se ha visto claramente influenciada por las distintas fases económicas vividas en nuestro país, disminuyendo en tiempos de crisis y aumentando en tiempos de prosperidad económica.

Las tasas especificas de ocupación femenina correspondientes a los grupos (30-34) y (35-39) han seguido un comportamiento distinto, aumentando sus tasas de ocupación entre 1980 y 1995 en un 61,2 y un 54 por 100, respectivamente, lo cual indica que a pesar de las diferentes fases económicas vividas a lo largo del período sus tasas se han visto gradualmente aumentadas sin presentar síntomas de debilitamiento (gráfico VII).

Las tasas especificas de paro femenino correspondientes a estos grupos de edad (20-39) presentan un gran aumento, tal como representa el gráfico VIII. La cifra más alta observada en 1995 es la correspondiente al grupo de edad 2024 , de un 46,7 por 100 de la población activa. No obstante, el aumento mayor entre 1980 y 1995 lo ha experimentado la tasa correspondiente al grupo de edad (35-39) con un incremento del 511 por 100 (4,3 por 100 en 1980 y 26,3 por 100 de la población activa en 1995).

Los datos que aquí se presentan, agregados, reflejan la evolución del mercado de trabajo femenino a nivel macro. La principal limitación que tal análisis tiene es la imposibilidad de establecer un vínculo entre las mujeres, dependiendo de su actividad económica (ocupadas, paradas e inactivas) y el número de hijos que han tenido. Tampoco se puede saber si la evolución de las cifras observadas en las tasas responden, a lo largo del tiempo, al mismo colectivo de mujeres o si, por el contrario, son resultado de múltiples variaciones en su composición. En el siguiente apartado se expone la forma posible de establecer vínculos entre estas dos variables con las fuentes de datos disponibles en España.

\section{LAS INTERACCIONES ENTRE ACTIVIDAD FEMENINA Y FECUNDIDAD}

Tal como se ha descrito en la Introducción, desde que la fecundidad inició su descenso más abrupto, llegando a alcanzar niveles por debajo del reemplazo generacional, la incorporación masiva de la mujer al mercado de trabajo ha sido y es considerada como un factor determinante. Aunque la dirección causal entre estas dos variables no parezca todavía clara, las interacciones entre las mismas parecen indiscutibles al coincidir cronológicamente el espacio en el que la mujer puede trabajar y tener hijos (Bernhardt, 1993).

El estudio más ambicioso que ha pretendido analizar la relación entre actividad femenina y fecundidad ha sido el publicado por la Dirección General V de la Comisión Europea (1990) llevado a cabo en cinco países (Alemania, Francia, Inglaterra, Italia y Suecia). Italia, Suecia e Inglaterra adoptaron en sus 
estudios el modelo de análisis de elección racional (Escuela de ChicagoColumbia) basado en la combinación de variables (actividad femenina y fecundidad). El estudio francés difiere de tal modelo convencional al incluir la importancia dada al nivel de vida de la unidad familiar (ingresos y nivel educativo) y su relación con el número de hijos. El análisis alemán va más allá incluyendo factores psico-sociales a los factores económicos, sociológicos y culturales. No obstante, y a pesar de las diferencias metodológicas, ningún país consiguió demostrar evidencia empírica sobre un nexo estable y directo entre ambas variables en alguna dirección.

¿Cómo se debe proceder entonces al análisis de la interacción entre actividad femenina y fecundidad sabiendo que ambas variables están en continua conexión y sabiendo que no se ha podido establecer una relación directa de causalidad entre ambas?

La forma ideal (y única) de poder mostrar resultados relevantes es llevando a cabo un estudio longitudinal (no retrospectivo) en el que se pueda seguir la trayectoria profesional de la mujer y su comportamiento reproductivo durante un espacio prolongado de tiempo con el fin de esclarecer la interacción entre ambas variables. Hasta la fecha, no existe ningún estudio en España de esas características. Ahora bien, ¿existen datos en nuestro país a nivel macro que nos puedan brindar indicios sobre qué ha sucedido entre estas dos variables entre 1980 y 1995 ?

El Movimiento Natural de la Población contiene una clasificación del número de nacimientos según la actividad económica y edad de la madre. Esta distinción se realiza entre activas e inactivas (recuérdese que activas comprende ocupadas y paradas, mientras que inactivas —en el caso que nos ocupa, mujeres entre dieciséis y cuarenta y nueve años de edad-, engloba, principalmente, a estudiantes y amas de casa ${ }^{6}$ ).

El cálculo que se ha realizado ha sido: dividir el número de nacidos en cada grupo de edad específico, según la actividad económica de la madre por el número de mujeres en ese grupo de edad (distinguiendo entre activas e inactivas) en ese mismo año. Este cálculo se ha hecho con los datos correspondientes a 1980 y 1995 . Las tasas resultantes permiten proceder a comparaciones.

A tenor de los datos expuestos en el gráfico IX, las mujeres activas pertenecientes al grupo de edad (20-24) presentan un descenso en el número de hijos nacidos entre los años 1980 y 1995 , de un 80 por 100 (55 nacimientos en 1980 por cada 1.000 mujeres activas y 11 nacimientos por cada 1.000 mujeres activas en 1995). A continuación, el grupo de mujeres activas entre veinticinco y veintinueve años de edad presenta un descenso del 51 por 100. Las mujeres activas entre treinta y treinta y cuatro años de edad presentan en el mismo

${ }^{6}$ La población inactiva abarca a todas las personas de dieciséis y más años, no clasificadas como ocupadas o paradas. Comprende las siguientes categorías funcionales: personas que se ocupen de su hogar, estudiantes, jubilados o retirados, personas que reciben una pensión distinta de la de jubilación, personas que realizan sin remuneración trabajos sociales, actividades de tipo benéfico, etc., e incapacitados para trabajar. 


\section{GRÁFICO IX}

Número de nacimientos por cada 1.000 mujeres activas y según grupos de edad (1980-1995)

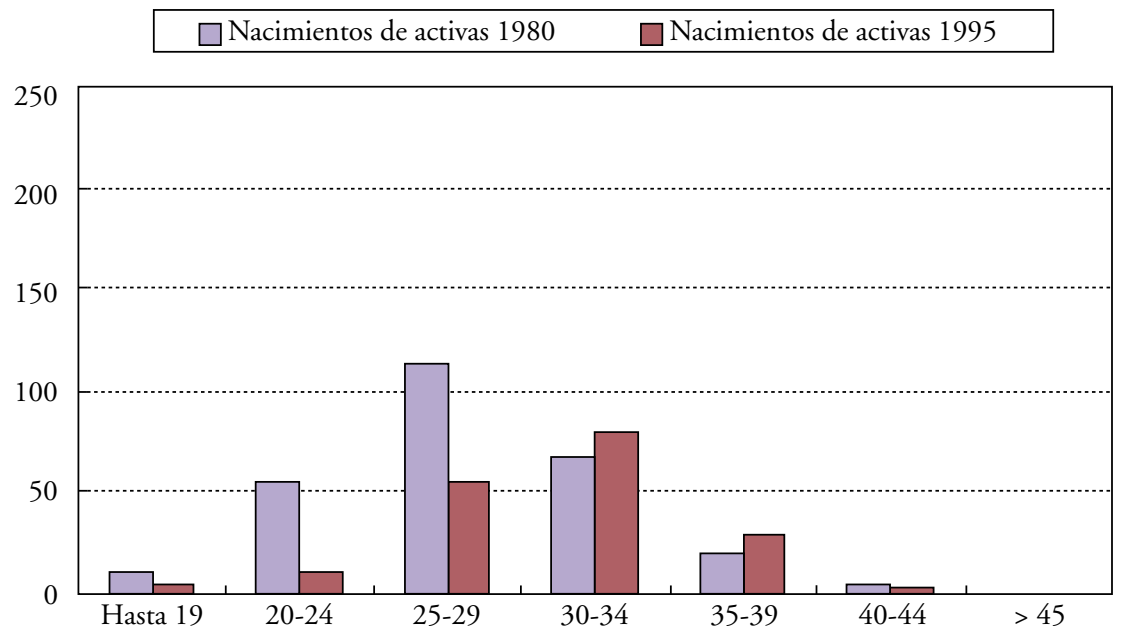

\section{GRÁFICO X}

Número de nacimientos por cada 1.000 mujeres inactivas y según grupos de edad (1980-1995)

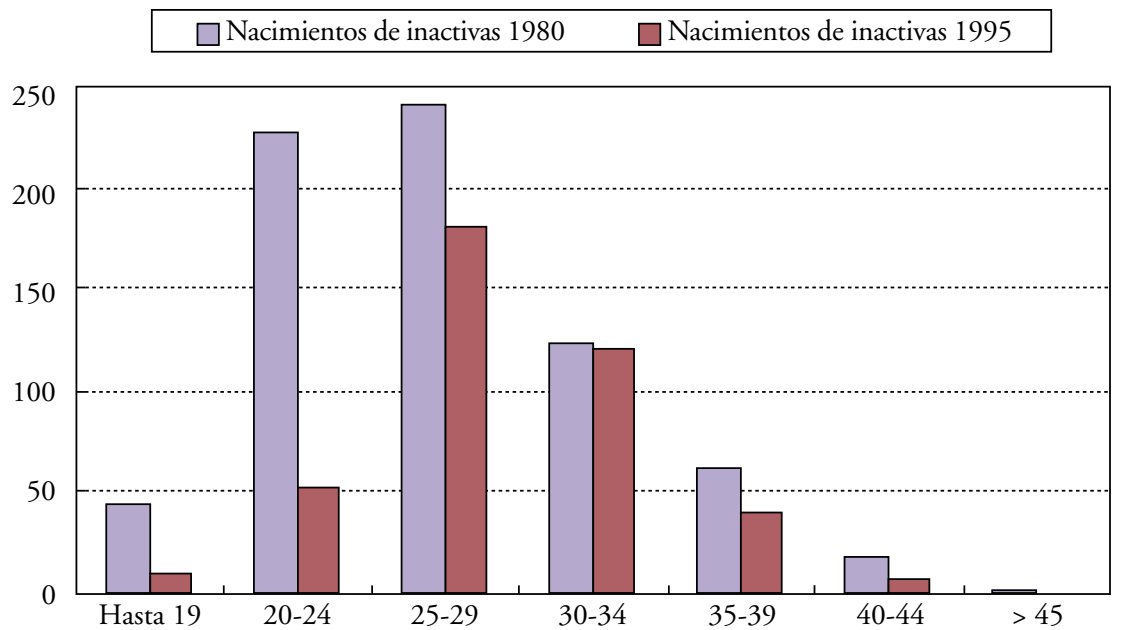

FUENTE: Elaboración propia a partir de los datos publicados en el Movimiento Natural de Población y EPA (medias anuales), INE. 


\section{GRÁFICO XI}

Número de nacimientos por cada 1.000 mujeres según la actividad económica y edad de la madre en 1980

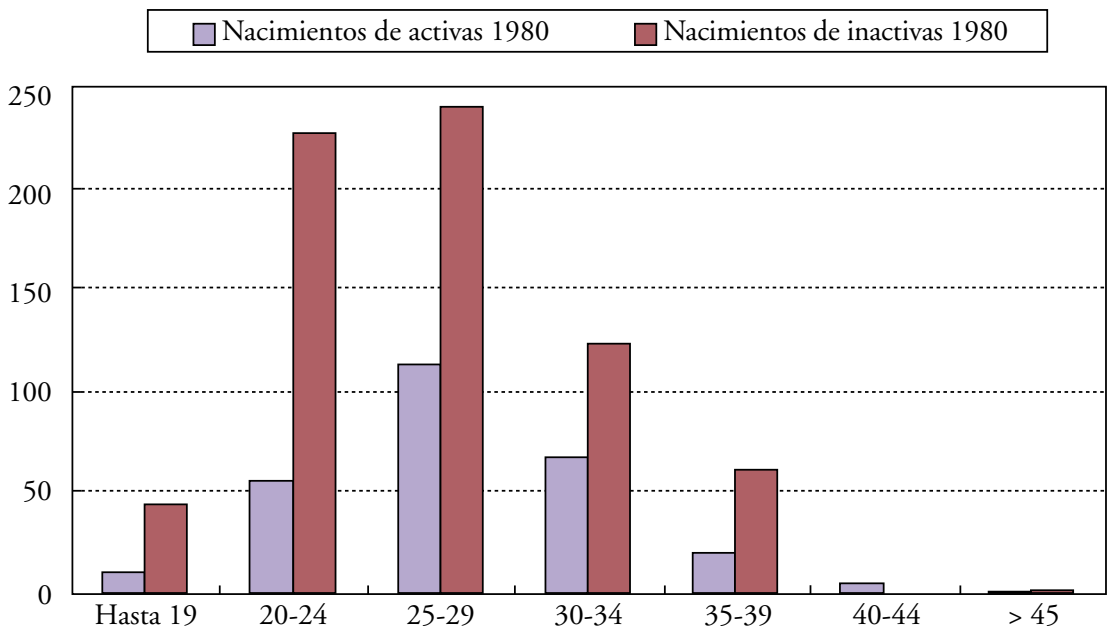

\section{GRÁFICO XII}

Número de nacimientos por cada 1.000 mujeres según la actividad económica y edad de la madre en 1995

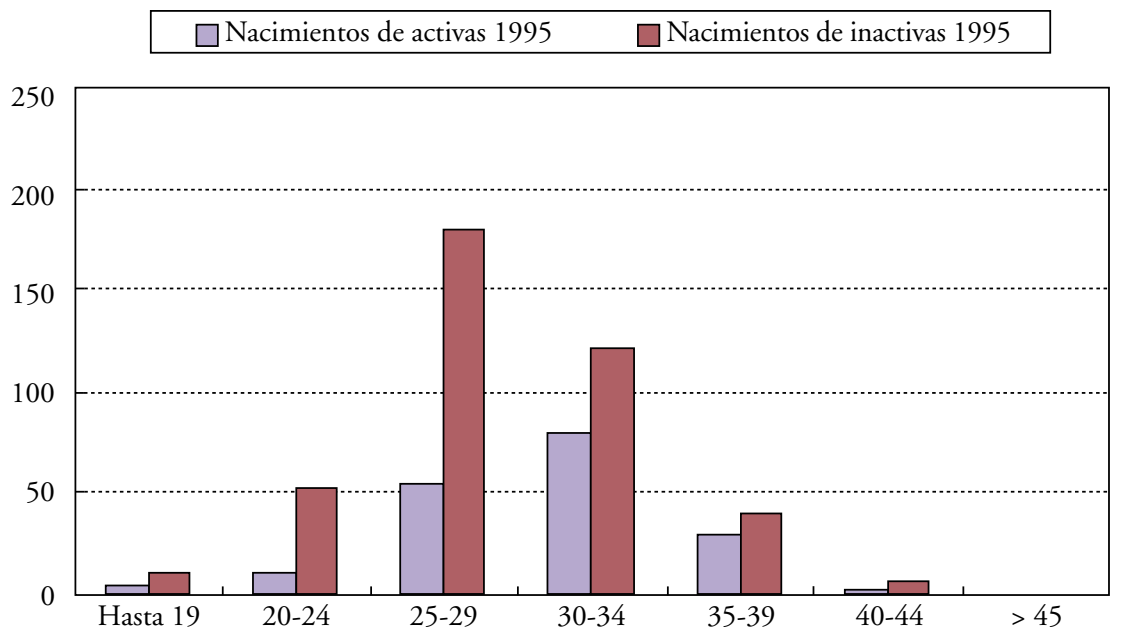

FUENTE: Elaboración propia a partir de los datos publicados en el Movimiento Natural de Población y EPA (medias anuales), INE. 
período de tiempo un ascenso en el número de nacimientos del 18 por 100 . Este aumento se ve acompañado del incremento en la tasa perteneciente a mujeres activas pertenecientes al grupo de edad (35-39) de un 45 por 100, pasando de tener 20 hijos por cada 1.000 mujeres en 1980 a 29 hijos por cada 1.000 mujeres en 1995. Aunque no pertenezca al grupo de mujeres estudiado, la variación del grupo de edad de mujeres hasta diecinueve años requiere mención; en el período estudiado (1980-1995) ve su tasa reducida en un 60 por 100 , teniendo en 1995 una tasa de cuatro nacimientos por cada 1.000 mujeres en su grupo frente a los 10 observados en 1980 .

Las cifras que presenta el gráfico X describen la evolución en el número de nacimientos de mujeres inactivas. Destaca también aquí (al igual que lo observado en el gráfico IX) la reducción de la tasa perteneciente el grupo de mujeres activas menores de diecinueve años, que en 1995 reduce su tasa en un 77 por 100, pasando de tener 44 hijos por cada 1.000 mujeres inactivas en 1980 a 10 por cada 1.000 mujeres inactivas en 1995 . El grupo de mujeres inactivas pertenecientes al grupo de edad (20-24) presenta una disminución en 1995 en su tasa del 77 por 100 respecto a la observada en 1980, pasando de tener en 1980 227 hijos por cada 1.000 mujeres inactivas a 52 hijos por cada 1.000 mujeres inactivas en 1995. El siguiente grupo de mujeres entre veinticinco y veintinueve años de edad presenta una disminución del 25 por 100 en el mismo período. El grupo de edad (30-34) es el único que no presenta apenas variaciones en los quince años estudiados.

La tasa resultante del número de hijos entre las mujeres entre veinte y treinta y nueve años (grueso de la población femenina en el que se encuentran el 90 por 100 de los nacimientos en 1980 y el 95 por 100 en 1995), dependiendo de su actividad económica es la siguiente: las mujeres activas pasan de tener 65 nacimientos en 1980 por cada 1.000 mujeres activas a 44 nacimientos por cada 1.000 mujeres activas en 1995; las mujeres inactivas tenían en 1980 154 hijos por cada 1.000 mujeres de sus mujeres, y en 1995, 75 hijos por cada 1.000 .

Atendiendo al grupo de mujeres en edades comprendidas entre veinte y treinta y nueve años y a su actividad económica, se puede observar en estos dos gráficos XI y XII un cambio significativo en cuanto a las diferencias observadas entre ambos colectivos (mujeres activas e inactivas) en su comportamiento reproductivo entre 1980 y 1995.

Para proceder a valoraciones respecto a las variaciones observadas en este período (1980-1995) se ha hallado la razón entre el número de nacimientos de mujeres inactivas y el número de nacimientos de activas en 1980 para los grupos correspondientes a las mujeres en edades comprendidas entre los veinte y treinta y nueve años, y se ha procedido de igual manera con las cifras correspondientes a 1995 .

Tal como se observa en los gráficos XI y XII, en 1980 las diferencias entre el número de nacimientos entre las mujeres activas e inactivas pertenecientes a los grupos de mujeres en edades comprendidas entre veinte y veintinueve años 
eran menores que las observadas en 1995. En 1980 hay 227 nacimientos por cada 1.000 mujeres inactivas y 55 por cada 1.000 activas entre las mujeres entre veinte y veinticuatro años de edad. En 1995 hay 52 nacimientos por cada 1.000 mujeres inactivas y 11 por cada 1.000 mujeres activas para el mismo grupo. Los nacimientos observados entre las mujeres de veinticinco y veintinueve años de edad pasan de ser en 1980, para las mujeres inactivas, de 240 por cada 1.000 mujeres a 180 en 1995, mientras que las mujeres activas ven reducido su número de 113 nacimientos por cada 1.000 en 1980 a 55 por cada 1.000 .

Estas diferencias observadas entre las mujeres activas e inactivas entre 1980 y 1995 para las mujeres de veinte a veintinueve años contrastan con las pertenecientes a las mujeres entre treinta y treinta y nueve años. En 1995 las diferencias observadas entre activas e inactivas son menores que las mismas en 1980. Los nacimientos entre las mujeres activas de treinta a treinta y cuatro años en 1980 eran de 67 por cada 1.000 de ellas, y en 1995, 79 nacimientos por cada 1.000 mujeres del mismo grupo de activas. Esta progresión también se observa para las mujeres activas entre treinta y cinco y treinta y nueve años que pasaron de tener en 1980 una cifra de 20 nacimientos por cada 1.000 mujeres a 29 nacimientos por cada 1.000 mujeres en 1995. Las mujeres inactivas de treinta a treinta y cuatro años tuvieron una tasa de 123 nacimientos por cada 1.000 mujeres en 1980, y en 1995 mantuvieron casi el mismo número (120). Las pertenecientes al siguiente grupo de edad (35-39), también inactivas, vieron reducido su número en un 36 por 100, pasando de tener 61 nacimientos por cada 1.000 de sus mujeres en 1980 a 39 nacimientos en 1995.

En resumen, entre 1980 y 1995 las mujeres entre veinte y treinta y nueve años inactivas redujeron su tasa de fecundidad en mayor proporción que las activas. Las primeras pasaron de tener 154 nacimientos por cada 1.000 mujeres en 1980 a 75 en 1995 —una disminución del 51 por 100 - y las segundas, las activas, redujeron su tasa de 65 nacimientos por cada 1.000 mujeres a 44 en 1995 - una reducción del 32 por 100- (datos representados en los gráficos IX y X). Ahora bien, para las mujeres en edades comprendidas entre veinte y veintinueve años, la proporción de nacimientos de mujeres activas, respecto al número de nacimientos de mujeres inactivas en 1980 , es mayor a la observada en 1995 (gráficos XI y XII). No obstante, y aun sin compensar las diferencias observadas entre las mujeres de veinte a veintinueve años, la diferencia entre la proporción de nacimientos de mujeres activas respecto al número de nacimientos de mujeres inactivas entre de treinta a treinta y nueve años se ve reducida en 1995, comparándola a la observada en 1980.

Las limitaciones que esta comparación presenta son varias. El problema mayor: saber cuántas mujeres consideradas «inactivas» han permanecido y cuánto tiempo han permanecido "paradas» anteriormente. Tampoco es posible saber el orden que estos nacimientos tienen entre el número total de hijos de las madres. 


\section{CONCLUSIONES}

El índice sintético de fecundidad o promedio de hijos por mujer era de 2,2 en 1980 y en 1995 de 1,2 (gráfico II).

En el gráfico IV se observa que si bien la tasa de actividad total femenina presentaba un aumento del 33 por 100 en el período estudiado de 1980 hasta 1995, alcanzando el 36,2 de la población potencialmente activa en 1995, atendiendo a las tasas de actividad específicas por grupos de edad, las mujeres entre treinta y treinta y nueve años han incrementado su participación en el mercado de trabajo en un 100 por 100 en el mismo período de tiempo. La tasa de actividad femenina del grupo de edad 25-29 se incrementó en un 70 por 100 y la tasa correspondiente a las mujeres de edades comprendidas entre veinte y veinticuatro años, a pesar de distintas variaciones a lo largo del período, en 1995 presenta una tasa similar a la de 1980 (gráfico VI).

La evolución de la ocupación y del paro presenta dos trayectorias muy distintas entre 1980 y 1995. Respecto a la ocupación femenina (gráfico VII) el grupo (20-24) es el único que llega a 1995 con una disminución en su tasa de ocupación del 26,3 por 100 respecto a la tasa correspondiente a 1980. El grupo (25-29) finaliza el período en 1995 con un aumento del 20,3 por 100 respecto a la tasa observada en 1980 . Ambas tasas de ocupación (20-24) y (25-29) presentan grandes variaciones a lo largo de todo el período estudiado. Las tasas correspondientes a los grupos de mujeres en edades comprendidas entre 30-34 y 35-39 parecen haber seguido un comportamiento distinto. Ambas tasas han ascendido sin interrupción en el período observado. El grupo 30-34 ha experimentado un aumento en 1995 de un 61,2 por 100, en relación a la tasa observada en 1980. El grupo 35-39 concluye el período con un aumento en su tasa del 54 por 100, comparando su tasa a la observada en 1980.

La tendencia al alza de todas las tasas de paro específicas femeninas representadas en el gráfico VIII, en el período 1980-1995 es significativa. La tasa de paro correspondiente al grupo (20-25), si bien es la más alta de todas, tanto en 1980 (23,5 por 100 de la población activa) como en 1995 (46,8 por 100 de la población activa), es la que menos aumento ha sufrido al final del período (99 por 100). Le sigue la tasa del grupo (25-29), con un aumento del 226 por 100; la del grupo (30-34), con un aumento del 250 por 100 , y por último, la tasa de paro correspondiente al grupo de treinta y cinco a treinta y nueve años, que experimenta una subida del 511 por 100 .

Ahora bien, de las interacciones entre estas dos variables estudiadas en el punto 5 (fecundidad y la actividad femenina) de las mujeres entre veinte y treinta y nueve años, los resultados obtenidos y representados en los gráficos IX, X, XI y XII permiten la siguiente lectura:

a) La reducción en el número de nacimientos ha sido mayor para las mujeres inactivas que para las activas (una reducción del 51 por 100 para las inactivas y una reducción del 32,5 por 100 para las activas en 1995, en relación a las cifras observadas en 1980). 
b) La razón observada del número de nacimientos de mujeres activas respecto al número de nacimientos de mujeres inactivas en 1980 es mayor a la observada en 1995 (gráficos XI y XII).

La razón observada del número de nacimientos de mujeres activas (ocupadas + paradas) respecto al número de nacimientos de mujeres inactivas ha disminuido en 1995, comparada con la misma razón observada en 1980. De acuerdo a la hipótesis planteada y a tenor de los datos expuestos, se puede afirmar que existen indicios para creer que las dificultades para compaginar la vida laboral y la maternidad han aumentado en estos quince años y/o el paro ha contribuido a frenar el numero de nacimientos entre ellas.

En este trabajo se han analizado la relaciones que se pueden observar, a tenor de los datos disponibles y expuestos, entre estas dos variables (fecundidad y actividad femenina). Se ha considerado actividad femenina como variable a estudiar en relación con la fecundidad porque la incorporación masiva de la mujer española al mercado de trabajo es considerada (al igual que en el resto de los países industrializados) como el cambio más relevante en la estructura familiar.

Evaluando los resultados de acuerdo al modelo de elección racional presentado en este trabajo (preferencias $\rightarrow$ limitaciones $\rightarrow$ comportamiento final), inserto en la teoría preferencial, este estudio presenta el incremento de la tasas específicas de actividad femenina (para mujeres en edades comprendidas entre veinte y treinta y nueve años) en España entre 1980 y 1995 como determinante en el cambio de preferencias que las españolas tienen. El deseo en cuanto al número de hijos no ha variado entre 1980 y 1995; tan sólo un 1 por 100 de los españoles no desea tener hijos y tan sólo un 5 por 100 desea tener un hijo único, la mayoría se inclina entre dos y tres hijos. El deseo mayormente compartido es compaginar la vida laboral con la maternidad. El comportamiento final (reproductivo) representado en el promedio de hijos por mujer es de 1,5 hijos ${ }^{7}$. Este análisis lleva a pensar, como se decía, que el aumento observado en las cifras del paro y las dificultades para compaginar la vida laboral y la maternidad parecen ser limitaciones ante el deseo de tener hijos, contribuyendo así a la explicación de la brecha existente entre el número de hijos que los españoles desean y los hijos que realmente tienen.

Los resultados de este estudio pueden también constituirse como base empírica en las teorías que han manifestado que parte del descenso de la fecundidad ocurrido en España en los últimos lustros podría ser atribuible a una estrategia protagonizada por las mujeres frente a la enorme dificultad que supone compaginar trabajo y familia, caracterizada por una drástica reducción de su fecundidad (Flaquer, 1998: 144-145; Alberdi, 1999:149).

7 Dato tomado de la última estimación del tamaño de cohorte (para las nacidas a partir de 1960 hasta 1965), en Recent Demographic Changes, Consejo de Europa, 1998. 


\section{BIBLIOGRAFÍA}

Alberdi, I. (1999): La nueva familia española, Taurus, Madrid.

BECKER, G. S., y BARRO, R. J. (1988): "A Reformulation of the Economic Theory of Fertility», en Quarterly Journal of Economics, Harvard College and the Massachusetts Institute of Technology, vol. CIII, febrero, pp. 1-25.

Becker, G. S. (1981): A Treatise on the Family, Harvard University Press, pp. 245-248.

- (1976): The economic approach to human behavior, Chicago, Prentice Hall.

- (1960): «An Economic Analysis of Fertility», en Demographic and Economic Change in Developed Countries, en edición de the Universities-National Bureau Committee for Economic Research. Princenton University Press (for the National Bureau of Economic Research), pp. 209-31.

Bernhardt, E. M. (1993): "Fertility and Employment», en European Sociological Review, núm. 9, Oxford University Press, pp. 25-42.

Cebrián, I.; Moreno, G., y TOHARIA, L. (1997): «Las transiciones laborales de las mujeres casadas en España, 1987-1996», en ICE, núm. 760, Ministerio de Economía y Hacienda, Madrid, pp. 129-141.

CES (CONSEJO ECONÓMICO y SOCIAL) (1994): La situación de la mujer en la realidad socio-laboral española, Informe núm. 3, Madrid.

CIS (Centro De Investigaciones Sociológicas) (1981): Evolución del sistema de valores en España, Estudio núm. 1263, Madrid.

- (1985): Actitudes y opiniones de los españoles frente a la natalidad, Estudio núm. 1474, Madrid.

- (1989): Encuesta general de población, Estudio núm. 1841, Madrid.

- (1991): Interrupción voluntaria del embarazo, Estudio núm. 1968, Madrid.

- (1994): Familia (International Social Survey Programme), Estudio núm. 2113. Madrid.

COMisión de las Comunidades Europeas (1991): "Study on the Relationship between Female Activity and Fertility», Synthesis Report, DG V, (V/639/91), enero.

CONSEJO DE Europa (1998): Cambios demográficos recientes.

DurÁN, M. A. (1996): «El trabajo invisible en España: aspectos económicos y normativos», en Revista de Estudios Sociales y de Sociología Aplicada, núm. 105, Madrid, pp. 137-157.

EnCUesta de Población ACTIVA (EPA): Series homogeneizadas correspondientes a actividad, ocupación y desempleo, 1980-1995, Instituto Nacional de Estadística, Madrid.

EsPINA, A. (1990): «La integración laboral de la mujer en perspectiva histórica», en Empleo, democracia y relaciones industriales en España, Ministerio de Trabajo y Seguridad Social, Madrid, pp. 93-183.

FlaQUeR, L. (1998): El destino de la familia, Ariel, Barcelona.

GARRIDO, L. (1992): Las dos biografias de la mujer en España, Instituto de la Mujer, núm. 33, Ministerio de Asuntos Sociales, Madrid.

HAKIM, C. (1998): «Developing a sociology for the twenty-first century: Preference Theory», en British Journal of Sociology, núm. 49 Issue núm. 1, London School of Economics, marzo, pp. 137-143.

Movimiento Natural de la Población (MNP): Nacimientos según edad y actividad económica de la madre, 1980-1995, Instituto Nacional de Estadística, Madrid.

TOHARIA, L. (1991): «El paro femenino en España: algunos elementos para el análisis», en Revista de Economía y Sociología del Trabajo, núms. 13-14, Madrid, pp. 74-87. 


\begin{abstract}
Spain has one of the lowest TFR (Total Fertility Rate, average children per woman) in the world. The female labour participation rate is also one of the lowest compared to the rest of the industrialized countries. However, the female labour participation rate is compounded by two opposite phenomena: employment and unemployment.

After reviewing studies that have shown evidence about the relationship existing between fertility and female labour participation, this paper presents a first approach, at the macro level, to the existing labour market data in Spain from 1980 till 1995 in order to clarity which possible influence could have had as determinant of fertility.
\end{abstract}

